AperTO - Archivio Istituzionale Open Access dell'Università di Torino

\title{
3q26.33-3q27.2 microdeletion: a new microdeletion syndrome?
}

\section{This is the author's manuscript}

Original Citation:

Availability:

This version is available http://hdl.handle.net/2318/150798

since 2015-07-22T16:59:26Z

Published version:

DOI:10.1016/j.ejmg.2013.01.005

Terms of use:

Open Access

Anyone can freely access the full text of works made available as "Open Access". Works made available under a Creative Commons license can be used according to the terms and conditions of said license. Use of all other works requires consent of the right holder (author or publisher) if not exempted from copyright protection by the applicable law. 


\section{(28) \\ UNIVERSITÀ DEGLI STUDI DI TORINO}

This Accepted Author Manuscript (AAM) is copyrighted and published by Elsevier. It is posted here by agreement between Elsevier and the University of Turin. Changes resulting from the publishing process such as editing, corrections, structural formatting, and other quality control mechanisms - may not be reflected in this version of the text. The definitive version of the text was subsequently published in [Eur J Med Genet. 2013 Apr;56(4):216-21. doi: 10.1016/j.ejmg.2013.01.00

http://www.sciencedirect.com/science/article/pii/S1769721213000232].

You may download, copy and otherwise use the AAM for non-commercial purposes provided that your license is limited by the following restrictions:

(1) You may use this AAM for non-commercial purposes only under the terms of the CC-BY-NC-ND license.

(2) The integrity of the work and identification of the author, copyright owner, and publisher must be preserved in any copy.

(3) You must attribute this AAM in the following format: Creative Commons BY-NC-ND license (http://creativecommons.org/licenses/by-nc-nd/4.0/deed.en), [+ Digital Object Identifier link to the published journal article on Elsevier's ScienceDirect ${ }^{\circledR}$ platform $]$ 


\section{3q26.33-3q27.2 MICRODELETION: A NEW MICRODELETION SYNDROME?}

Giorgia Mandrile ${ }^{a}$, Anna Dubois $^{b}$, Jodi D. Hoffman $^{c}$, Vera Uliana $^{a}$, Emilio Di Maria $^{a, d}$, Michela Malacarne ${ }^{\mathrm{e}}$, Domenico Coviello ${ }^{\mathrm{e}}$, Francesca Faravelli ${ }^{\mathrm{a}}$, Simon Zwolinski ${ }^{\mathrm{b}}$, Stephen Hellens $^{b}$, Michael Wright ${ }^{\mathrm{b}}$, Francesca Forzano ${ }^{\mathrm{a} *}$.

a Division of Medical Genetics, Galliera Hospital, Genova, Italy

${ }^{b}$ Northern Genetics Service, Newcastle upon Tyne Hospitals, Newcastle upon Tyne, United Kingdom

${ }^{c}$ Division of Genetics, Floating Hospital for Children, Tufts Medical Center, Boston, MA

${ }^{d}$ Department of Health Sciences, University of Genova, Italy

${ }^{\text {e }}$ Laboratory of Human Genetics, Galliera Hospital, Genova, Italy

\section{corresponding author}

* Francesca Forzano, M.D.

Division of Medical Genetics, Galliera Hospital

Via Volta, 6 - 16128 Genova - Italy

e-mail: forzanof@galliera.it - phone +39 0105634367 - fax +39 01057481026

\section{keywords}

3q26.33-3q27.2 microdeletion syndrome

abnormal dentition

developmental delay

growth retardation 
Array-CGH

Running title: 3q26.33-3q27.2 microdeletion

Type of article: Clinical research

Word count - excluding title page, abstract, references, figures and tables: 2233

Abstract: 77 words

Pictures/Tables: 2 pictures +1 table

References: 9 


\section{ABSTRACT}

We describe three unrelated patients of European descent carrying an overlapping 3q26.333q27.2 microdeletion who share common clinical features: neonatal hypotonia, severe feeding problems, specific facial features, abnormal dentition, recurrent upper airways infections, developmental delay and severe growth impairment. One of the patients carries a smaller deletion and presents a milder phenotype. We propose that $3 q 26.33-3 q 27.2$ microdeletion may represent a novel condition caused by the haploinsufficiency of dosage sensitive genes, several of which are involved in brain development. 


\section{INTRODUCTION}

Intellectual disability (ID), isolated or associated with congenital anomalies, is a significant clinical and social problem, involving $1-3 \%$ of the general population worldwide [1]. Chromosomal microarray techniques can identify a submicroscopic unbalanced chromosomal rearrangement in up to $15 \%$ of patients affected by ID [2], occasionally leading to the identification of 'new' microdeletion/duplication syndromes. International databases of chromosome imbalance such as DECIPHER (http://decipher.sanger.ac.uk) are extremely useful in matching patients carrying similar chromosomal rearrangements.

Here we describe three unrelated patients of European descent, 2 of them reported in DECIPHER data base, carrying an overlapping 3q26.33-3q27.2 microdeletion and sharing common clinical features. We therefore suggest that 3q26.33-3q27.2 microdeletion may represent a novel condition caused by the haploinsufficiency of dosage sensitive genes within this region.

\section{PATIENT DATA}

\subsection{Patient 1}

Patient 1 was the only child of healthy non consanguineous parents who presented at 2 years and 8 months of age. Intrauterine growth restriction (IUGR) was noted early in the pregnancy; biochemical screening for Down syndrome and serial ultrasound scan did not reveal placental or fetal abnormalities. The mother reported normal fetal movements.

Cesarean section was performed at 32 weeks gestation due to growth arrest: birth weight was $1380 \mathrm{~g}\left(10-25^{\text {th }}\right.$ centile, according to Hall growth curves [3]), birth length $39.5 \mathrm{~cm}$ (10$25^{\text {th }}$ centile), head circumference (OFC) $29.5 \mathrm{~cm}\left(50^{\text {th }}\right.$ centile). In the neonatal period, he showed bronchopulmonary dysplasia of prematurity, marked hypotonia, muscular 
hypotrophy, inguinal hernia and patent ductus arteriosus, which resolved after pharmacological treatment. Brain ultrasound, electroencephalography (EEG), routine blood analysis, plasma aminoacids and mucopolysaccharide screening were normal.

The baby had severe feeding problems and gavage feeding was used for the first 2 months of life. Feeding difficulties have only slightly improved. At 6 years of age, he is not yet able to chew and can only eat homogenized food. Oral aversion and lack of appetite are consistently reported. Gastroesophageal reflux and frequent vomiting require continued omeprazole treatment.

He also presented with recurrent upper airway infections, bladder diverticula, vesicoureteric reflux and retractile right testicle which required orchidopexy.

Results of Auditory Brainstem Response (ABR) were inconclusive due to the patient's poor cooperation, however the parents did not suspect hearing difficulties. Ophthalmological examination revealed mild myopia and astigmatism (wears corrective lenses) and normal fundus oculi.

He wears orthopedic insoles for pes planus.

Development was delayed: head control was achieved at 10 months of age, he sat at 17 months of age and babbled at 18 months of age. At 6 years of age, he has not developed speech and does not have bladder or bowel sphincter control. Teeth eruption was markedly delayed: at 6 years of age dentition is still incomplete, with the upper jaw more involved.

Growth parameters at 2 years 8 months and 6 years of age all plotted between -3 and -4 standard deviations (SD) (Table 1). Parental stature was at the $25^{\text {th }}-50^{\text {th }}$ centile (mother $160 \mathrm{~cm}$ and father $173 \mathrm{~cm})$.

On physical examination we noted thin skin with very little subcutaneous fat, mild pectus carinatum, mild kyphosis, joint laxity, clinodactyly of the fourth toes. The third toes overlap the fourth toes (also reported in the father).

\subsection{Patient 2}


Patient 2 was the second child born to healthy unrelated parents. He was first seen in clinic at one month of age. He is now eighteen years of age. He was noted to have IUGR and was born by emergency Cesarean section at 37 weeks gestation. He needed resuscitation at birth for poor respiratory effort. His birth weight was $1590 \mathrm{~g}\left(<3^{\text {rd }}\right.$ centile [3]) and his OFC at birth was $29.5 \mathrm{~cm}\left(<3^{\text {rd }}\right.$ centile [3]). He was hypotonic with a prominent nasal bridge, short philtrum, micrognathia and undescended testes. At three hours of age he had a tonic seizure with apnoea. He had several more seizures over the first 24 hours of life. He was started on phenobarbital and broad spectrum antibiotics and the seizures resolved. An EEG showed no background seizure activity, cranial ultrasound was unremarkable apart from a small cyst adjacent to the choroid plexus, and blood chemistries and metabolic screening were normal. G-banded karyotype was reported as $46, \mathrm{XY}$.

He was able to bottle feed initially, however, gastrostomy feeding was required from 2 to 13 years of age for poor weight gain. He had conductive hearing loss and required grommets. He has micropenis and cryptorchidism and required testosterone therapy at puberty. He has pes planus and abnormal foot position for which he wears orthotics.

His development was delayed. By 4 years of age he was walking and had several single words. He progressed to being able to speak in short sentences. He has a learning disability and behavioural difficulties.

His teeth were slow to erupt and by the age of fifteen years he still had his primary dentition, despite his adult teeth erupting. He has bilateral keratoconus. At the age of 16.75 years, his height was $147.6 \mathrm{~cm}(-4 \mathrm{SD})$ and his weight $30.8 \mathrm{~kg}(-3$ to $-4 \mathrm{SD})$.

\subsection{Patient 3}

Patient 2 was the second child of non-consanguineous healthy parents. Family history was non-contributory. She was evaluated at the genetics clinic at 11 years of age regarding a possible diagnosis of Williams-Beuren syndrome due to a history of failure to thrive, hypotonia, attention deficit disorder (ADHD) and an extremely friendly personality. The 
pregnancy was complicated by chronic polyhydramnios and intrauterine growth restriction. A level 2 ultrasound had shown possible problem with the kidneys (ultrasound report unavailable). During the pregnancy, cigarette smoking was reported (5-10 cigarettes per day). Due to the risk of preterm labor, the mother was given cortisone at 32 weeks gestation. The child was born at 38 5/7 weeks gestational age via Cesarean section secondary to breech presentation; birth weight was $1975 \mathrm{~g}\left(<<3^{\text {rd }}\right.$ centile [3]), length 43.82 $\mathrm{cm}\left(<<3^{\text {rd }}\right.$ centile [3]), OFC $32 \mathrm{~cm}\left(10-25^{\text {th }}\right.$ centile [3]). APGAR scores were 8/9. At birth the following features were noted: cutis aplasia of scalp $(2,5 \times 3,8 \mathrm{~cm})$, with underlying bony defect, hypotonia, edema of the genitals, and sacral dimple. She had poor suck and swallow with feeding issues resulting in projectile vomiting, often through the nose. She cried inconsolably, stiffened frequently and had gastroesophageal reflux requiring therapy with ranitidine and metoclopramide. She required multiple formula changes and required two to three hours to take two to three ounces of formula. For many years, she had difficulty growing, prompting cystic fibrosis screening which was negative. Her weight did not normalize until approximately nine to ten years of age and she has become overweight for height since that time.

Frequent episodes of abdominal pain, diarrhea and constipation were reported.

Primary teeth loss was delayed and teeth were small, pointed, and crowded; all but one required extraction. Moreover, salivary thickening was noted. She choked frequently when drinking.

The child has never had a seizure, but does stare for several minutes at a time. Brain MRI showed a $12 \mathrm{~mm}$ Chiari malformation, crowding of the foramen magnum, narrowing of the inferior fourth ventricle, limited flow of cerebrospinal fluid through the foramen magnum causing ventriculomegaly involving the third and lateral ventricles. Glasses were used because of astigmatism and myopia.

Frequent episodes of otitis media were reported, with intermittent decreased hearing 
secondary to fluid. She is very sensitive to loud noises, becoming anxious and upset. She was recently noted to have acanthosis nigricans and "pre-diabetes". She reportedly urinates frequently and drinks excessively. She has enuresis and frequent daytime incontinence. She has a history of hypermobility of the hips. She has a history of eczema.

Her development was delayed; she showed gross motor impairment with decreased hip strength and poor posture control with delays in fine motor skills. She walked at 20 month of age and language was slightly delayed. She had a learning disability and she required occupational, physical, speech therapy, and social skills training.

She excels in verbal areas, spelling, and reading, has average working memory, and has difficulty with maths and step-wise work. She learned to tie her shoes at age 11 years of age. She has inconsistent visual skills and poor writing skills. She was diagnosed with ADHD, is overly affectionate with those around her and has an extreme sense of empathy.

At 12 years 1 month of age, her height was at the $3^{\text {rd }}$ centile, OCF at $10^{\text {th }}$ centile, and weight at $50^{\text {th }}$ centile. Paternal stature was $178 \mathrm{~cm}\left(50-75^{\text {th }}\right.$ centile [3]) and maternal stature was $178 \mathrm{~cm}\left(>95^{\text {th }}\right.$ centile [3]).

On physical examination we noted frontal bossing and mild temporal narrowing. Ears were mildly simple and somewhat thickened, measuring $5.2 \mathrm{~cm}$ (-2SD). Eyes had mildly narrow horizontal openings with normal slant. She had fused lower incisors, mildly flat and short philtrum, and mild retrognathia. Her labia minora were hypoplastic with a hypoplastic pubic pad. Fingers were mildly tapered with mild flattening of the ulnar border. She had multiple freckles of the left forearm and café au lait spot of left lower flank with mildly decreased tone.

\section{METHODS AND RESULTS}

\subsection{Patient 1}

Array-CGH performed using Human Genome CGH Microarray Kit 4 x 44K (Agilent) 
detected a de novo 4.14 Mb microdeletion from 181.648.378 (3q26.33) to 185.786.898 (3q27.2). This result was confirmed through FISH (BAC - Sanger Center- RP11-63M3 3q27.1); the same FISH has been performed to analyze parents' samples. The deletion involves 43 genes (Genome assembly Feb. 2009 - UCSC hg19) (Fig. 1).

\subsection{Patient 2}

Array-CGH performed using a Sanger 1Mb BAC array (Build 36) detected a de novo 4.28 Mb microdeletion from 181.692.255 (3q26.33) to 185.969.168 (3q27.2). This result was confirmed by re analysis of the G-banded Karyotype which demonstrated that in hindsight the deletion was visible microscopically. The deletion involves 44 genes (Genome assembly Feb. 2009 - UCSC hg19) (Fig. 1). Parental samples were analyzed by. G-banded karyotype and these showed no evidence of the microdeletion. This confirmed that the deletion had arisen as a de novo event.

\subsection{Patient 3}

Array-CGH performed using Affymetrix 6.0SNP array kit detected a 2.09 Mb microdeletion from $183.047 .473(3 q 27.1)$ to $185.140 .522(3 q 27.2)$. This result was confirmed through FISH. The deletion involves 36 genes (Genome assembly Feb. 2009 - UCSC hg19) (Fig. 1). Maternal testing via FISH was normal (BAC-RP11-63G1 3q27.1-q27). Father unable to be tested to date.

\section{DISCUSSION}

Three patients are described with an overlapping 3q26.33-3q27.2 microdeletion, sharing specific features that could make this phenotype clinically recognizable (Fig. 2; Table 1). Patient 3 carries a smaller deletion, entirely embedded within the region deleted in the other two patients, and presents a milder phenotype, mainly with respect to intellectual disability and growth.

This disorder is possibly secondary to contiguous gene deletion. At least 40 genes are 
located within this region (Fig. 1). At least six genes may be involved in brain development and function, particularly: DCUN1D1, for which the mouse ortholog is expressed in proliferating neuroblasts [4]; DVL3, a regulator of cell proliferation and neuroblast specification [5]; several genes belonging to the serotonin receptor family (HTR3C, HTR3D, HTR3E); KLHL24, involved in functional regulation of glutamate receptors [6]; MAP6D1, a neuronal protein that binds microtubules and plays a role in synaptic function in neuritis [7]. Several of the genes included in the deletion have already been associated with human pathologies, with both autosomal recessive and dominant transmission. Our patients did not show any symptoms of autosomal recessive diseases associated with mutations in the genes mapping to this region (e.g. ALG3, MCCC1, EIF2B5, LIPH) and therefore we did not sequence the contralateral alleles.

Within the common deleted region is the gene THPO. Gain of function mutations in this gene have been shown to be responsible for hereditary thrombocythaemia [8,9].

Patient 1 showed reduced platelet concentration (127×10\%/ul, n.v. 150-400) and patient 3 had platelet concentration at the low end of normal $\left(168 \times 10^{3} / u l\right.$, n.v. 140-400). Further assessment of the possible role of deletion of THPO in thrombocytopenia may be appropriate.

CLCN2, a gene for which the mice knock-out model of its homolog demonstrates leukoencephalopathy [10] and degeneration of retinal and testicular cells, leading to male infertility is present in the deleted region [11]. The CLCN2 rat homolog is expressed in fetal lung and its expression rapidly decreases after birth; therefore its deficiency may be related to the neonatal respiratory distress [12] and testicular anomalies observed in our patients.

Several genes related to body growth are present in the deleted region. In all three patients PARL is deleted: the knock-out mouse (Parl -/-) shows growth retardation, cachexia and muscle atrophy. In patients 1 and 2 the ETV5 gene is deleted. These patients present with more severe growth impairment than patient 3. ETV5 is a member of the ETS transcription 
factors, ubiquitously expressed during development and adulthood. ETV5 homolog knockout mice show a progressive loss of spermatogonial stem cells and reduced body weight [13].

Several segmental duplications have been reported close to the deleted regions' breakpoints. The three deletions present in our patients did not share common breakpoints, and cannot be considered recurrent CNVs, but it could be postulated that the whole region might be susceptible to non-homologous recombinations leading to chromosomal rearrangements.

In conclusion, based on our observations, we propose that 3q26.33-3q27.2 microdeletion constitutes a new clinically recognizable syndrome characterized by growth deficiency, severe feeding problems, hypotonia, muscular hypotrophy, dysmorphic features, and intellectual disability.

Clinical and molecular characterization of additional patients with a similar chromosomal deletion are needed to further delineate the phenotype and refine the minimal critical region. 


\section{CONFLICT OF INTEREST}

Authors have no conflict of interest.

\section{ACKNOWLEDGMENTS}

We are grateful to the patients and their families for their collaboration. This work was partially granted by Galliera Hospital and Fondazione Carige (to F. Faravelli). V. Uliana is a PhD fellow at the University of L'Aquila, Italy. G. Mandrile is a PhD fellow at the University of Cagliari, Italy. Two cases were entered in the database for chromosomal aberration DECIPHER (Patient 1: 257773; Patient 2: 1495).

\section{REFERENCES}

[1] P.K. Maulik, M.N. Mascarenhas, C.D. Mathers, T. Dua, S. Saxena, Prevalence of intellectual disability: a meta-analysis of population-based studies, Res. Dev. Disabil. 32(2) (2011) 419-36.

[2] D.T. Miller, M.P. Adam, S. Aradhya, L.G. Biesecker, A.R. Brothman, N.P. Carter, D.M. Church, J.A. Crolla, E.E. Eichler, C.J. Epstein, W.A. Faucett, L. Feuk, J.M. Friedman, A. Hamosh, L. Jackson, E.B. Kaminsky, K. Kok, I.D. Krantz, R.M. Kuhn, C. Lee, J.M. Ostell, C. Rosenberg, S.W. Scherer, N.B. Spinner, D.J. Stavropoulos, J.H. Tepperberg, E.C. Thorland, J.R. Vermeesch, D.J. Waggoner, M.S. Watson, C.L. Martin, D.H. Ledbetter, Consensus statement: chromosomal microarray is a first-tier clinical diagnostic test for individuals with developmental disabilities or congenital 
anomalies, Am. J. Hum. Genetics 86 (2010) 749-764.

[3] J.G. Hall, J.E. Allanson, K.W. Gripp, A.M. Slavotinek, Handbook of physical measurements, Oxford Handbook.

[4] C. Mas, F. Bourgeois, A. Bulfone, B. Levacher, C. Mugnier, M. Simonneau, Cloning and expression analysis of a novel gene, RP42, mapping to an autism susceptibility locus on 6q16, Genomics. 2000 Apr 1;65(1):70-4.

[5] A. Pizzuti, F. Amati, G. Calabrese, A. Mari, A. Colosimo, V. Silani, L. Giardino, A. Ratti, D. Penso, L. Calza, G. Palka, G. Scarlato, G. Novelli, B. Dallapicolla, cDNA characterization and chromosomal mapping of two human homologs of the Drosophila dishevelled polarity gene, Hum. Molec. Genet. 5: 953-958, 1996.

[6] F. Laezza, T.J. Wilding, S. Sequeira, F. Coussen, X.Z. Zhang, R. Hill-Robinson, C. Mulle, J.E. Huettner, A.M. Craig, KRIP6: a novel BTB/kelch protein regulating function of kainate receptors, Mol Cell Neurosci. 2007 Apr;34(4):539-50.

[7] S. Gory-Faure, V. Windscheid, C. Bosc, L. Peris, D. Proietto, R. Franck, E. Denarier, D. Job, A. Andrieux, STOP-like protein 21 is a novel member of the STOP family, revealing a Golgi localization of STOP proteins, J. Biol. Chem. 281: 28387-28396, 2006.

[8] N. Ghilardi, A. Wiestner, M. Kikuchi, A. Ohsaka, R.C. Skoda, Hereditary thrombocythaemia in a Japanese family is caused by a novel point mutation in the thrombopoietin gene, Brit. J. Haemat. 107 (1999) 310-316.

[9] C. Graziano, S. Carone, E. Panza, F. Marino, P. Magini, G. Romeo, A. Pession, M. Seri, Association of hereditary thrombocythemia and distal limb defects with a thrombopoietin gene mutation, Blood 114 (2009) 1655-1657.

[10] J. Blanz, M. Schweizer, M. Auberson, H. Maier, A. Muenscher, C.A. Hubner, 
T.J. Jentsch. Leukoencephalopathy upon disruption of the chloride channel Clc-2, J. Neurosci. 27 (2007) 6581-6589.

M.R. Bosl, V. Stein, C. Hubner, A.A. Zdebik, S.E. Jordt, A.K. Mukhopadhyay, M.S. Davidoff, A.F. Holstein, T.J. Jentsch, Male germ cells and photoreceptors, both dependent on close cell-cell interactions, degenerate upon $\mathrm{ClC}-2 \mathrm{Cl}(-)$ channel disruption, EMBO J. 20 (2001) 1289-1299.

[12] C.B. Murray, M.M. Morales, T.R. Flotte, S.A. McGrath-Morrow, W.B. Guggino, P.L. Zeitlin, CIC-2: a developmentally dependent chloride channel expressed in the fetal lung and downregulated after birth, Am J Respir Cell Mol Biol. 12(6) (1995) 597604.

[13] H.N. Schlesser, L. Simon, M.C. Hofmann, K.M. Murphy, T. Murphy, R.A. Hess, P.S. Cooke, Effects of ETV5 (ets variant gene 5) on testis and body growth, time course of spermatogonial stem cell loss, and fertility in mice, Biol Reprod. 78(3) (2008) 483-9. 


\section{LEGENDS OF FIGURES}

Figure 1: schematic representation of 3q26.33-3q27.1 region with the minimal overlapping microdeletion and genes involved. Segmental duplications are indicated in pale grey when the level of similarity is $93-95.99 \%$, and dark grey when $90-92.99 \%$.

Figure 2: Patient 1 (A and B: age 6 years), Patient 2 ( $C$ and $D:$ age $8, E$ and F: age 11), Patient 3 ( $\mathrm{G}$ and $\mathrm{H}$ : age 1 years). Note common dysmorphisms: flat facial profile, medially sparse eyebrows, epicanthal folds, flat nasal bridge and tip, mild shortening of the philtrum Patient 1 and 2 share also downturned corners of mouth and small and spaced teeth at the lower jaw. In Patient 1, note also anteverted nares. 


\section{TABLE}

Table 1: comparison of patients' clinical features

\section{Phenotypic}

characteristic

Patient $1 \quad$ Patient 2

Patient 3

DECIPHER ID

257773

1495

Sex

Male

Male

Female

Age at last

examination
6 years
17 years
12 years

Size of the deletion

$4.14 \mathrm{Mb}$

$4.28 \mathrm{Mb}$

$2.09 \mathrm{Mb}$

IUGR

Yes

Yes

Yes

Birth parameters

Gestational age

32 w.g.

37 w.g.

$38+5$ w.g.

Birth weight

$1380 \mathrm{~g}(-1.22 \mathrm{SD})$

$1590 \mathrm{~g}(-3.03 \mathrm{SD})$

$1975 \mathrm{~g}(-3.53 \mathrm{SD})$

Birth length $39,5 \mathrm{~cm}(-1.21 \mathrm{SD})$

$43,82 \mathrm{~cm}(-4.12 \mathrm{SD})$

OCF at birth

$29,5 \mathrm{~cm}(-0.28 \mathrm{SD})$

$29,5 \mathrm{~cm}(-3.16 \mathrm{SD})$

$32 \mathrm{~cm}(-3.20 \mathrm{SD})$

Feeding problems

Yes

Yes

Yes

Slender habitus/little

subcutaneous fat

Yes

Yes

Until age 10 years

Height (at last

examination)

$98 \mathrm{~cm}(-3.68 \mathrm{SD}) \quad 147.6 \mathrm{~cm}(-4 \mathrm{SD}) \quad 136.2 \mathrm{~cm}(-2 \mathrm{SD})$

Weight (at last

examination)

$13 \mathrm{Kg}(-3.62 \mathrm{SD}) \quad 30.8 \mathrm{~kg}(-3 /-4 \mathrm{SD}) \quad 40.8 \mathrm{~kg}(0 \mathrm{SD})$

OCF (at last

$46 \mathrm{~cm}(-4.44 \mathrm{SD})$

$51.2 \mathrm{~cm}(-1.15 \mathrm{SD})$ 
examination)

dysmorphic features

flat facial profile

Yes

Yes

Yes

medially sparse

Yes

Yes

Yes

eyebrows

epicanthal folds

Yes

Yes

Yes

flat nasal bridge and

Yes

Yes

Yes

tip

anteverted nares

Yes

No

No

short philtrum

Yes

Yes

Mild

downturned corners

Yes

Yes

No

of mouth

Eyes

Myopia/astigmatism

Bilateral

keratoconus

Myopia/astigmatism

at 6 years dentition

at 15 years still had

pointed, delayed

is incomplete (upper

primary dentition,

falling out, wide

Teeth

jaw more

despite adult teeth

spaced, fused lower

compromised)

erupting

incisors

mildly simple and

Preauricular pit

thickened

Thin skin

Yes

Yes

No

Mildly tapered

Hand

Clinodactyly IV digit

fingers/flattening of

the ulnar border

Foot

Pes planus

Pes planus

Mild pes planus 
Mild kyphosis

Skeletal

Mild pectus

carenatum

Retractable lift

testicle

Genitalia

Yes

Not acquired

Not acquired

Severe

Normal

Behaviour

Neurology

Hypotonia

Other abnormalities

$$
\begin{gathered}
\text { Recurrent upper } \\
\text { airway infections } \\
\text { Patent ductus } \\
\text { arteriosus }
\end{gathered}
$$

Gastroesophageal

reflux

Inguinal hernia

Bladder diverticula hypermobility of the

hips

Hypoplastic labia minora and pubic Micropenis

pad

Yes

Speaks in sentences

Good

4 years

20 months

Learning disability,

Severe

borderline IQ

Hyperactivity

ADHD

Hypotonia

Hypotonia

Tonic seizure at

birth

Ventricular

malformations

Recurrent otitis

media

Mild hearing

Gastroesophageal

impairment

reflux (grommets)

Delayed puberty

(testosterone

therapy at puberty) 
20/14 